\title{
Promoting Early Presentation of Breast Cancer in Older Women: Implementing an Evidence-Based Intervention in Routine Clinical Practice
}

\author{
Lindsay J. L. Forbes, ${ }^{1}$ Alice S. Forster, ${ }^{1}$ Rachael H. Dodd, ${ }^{1}$ Lorraine Tucker, ${ }^{1}$ \\ Rachel Laming, ${ }^{1}$ Sarah Sellars, ${ }^{2}$ Julietta Patnick, ${ }^{2}$ and Amanda J. Ramirez ${ }^{1}$ \\ ${ }^{1}$ Promoting Early Presentation Group, Department of Psychological Medicine, Institute of Psychiatry, King's College London, \\ Capital House, 42 Weston Street, London SE1 3QD, UK \\ ${ }^{2}$ NHS Cancer Screening Programmes, Fulwood House, Old Fulwood Road, Sheffield S10 3TH, UK
}

Correspondence should be addressed to Lindsay J. L. Forbes, lindsay.forbes@kcl.ac.uk

Received 31 August 2012; Accepted 10 October 2012

Academic Editor: Marjan van den Akker

Copyright (C) 2012 Lindsay J. L. Forbes et al. This is an open access article distributed under the Creative Commons Attribution License, which permits unrestricted use, distribution, and reproduction in any medium, provided the original work is properly cited.

\begin{abstract}
Background. Women over 70 with breast cancer have poorer one-year survival and present at a more advanced stage than younger women. Promoting early symptomatic presentation in older women may reduce stage cost effectively and is unlikely to lead to overdiagnosis. After examining efficacy in a randomised controlled trial, we piloted a brief health professional-delivered intervention to equip women to present promptly with breast symptoms, as an integral part of the final invited mammogram at age $\sim 70$, in the English National Health Service Breast Screening Programme. Methods. We trained mammographers, who then offered the intervention to older women in four breast screening services. We examined breast cancer awareness at baseline and one month in women receiving the intervention, and also in a service where the intervention was not offered. Results. We trained 27 mammographers to deliver the intervention confidently to a high standard. Breast cancer awareness increased 7-fold at one month in women receiving the intervention compared with 2 -fold in the comparison service (odds ratio 15.2, 95\% confidence interval 10.0 to 23.2). Conclusions. The PEP Intervention can be implemented in routine clinical practice with a potency similar to that achieved in a randomised controlled trial. It has the potential to reduce delay in diagnosis for breast cancer in older women.
\end{abstract}

\section{Introduction}

Older women with breast cancer have poorer one-year relative survival than younger women [1] and are more likely to be diagnosed with advanced stage of disease [2]. Older age is a risk factor for delay in presentation in breast cancer [3]. Women over the age of 73 are not routinely invited for screening on the English National Health Service (NHS) Breast Screening Programme; most women with breast cancer of this age group therefore present symptomatically.

We have developed a brief intervention to promote early symptomatic presentation of breast cancer in older women (the Promoting Early Presentation (PEP) Intervention) [4]. It is a scripted one-to-one intervention, delivered to an older woman in a positive, collaborative, and motivational style by a health professional, providing the knowledge, motivation, confidence, and skills to present promptly on discovering a breast symptom. It is supported by a booklet which women are given to take home.

The PEP Intervention increased breast cancer awareness fourfold compared with usual care for up to two years in a randomised controlled trial, in which it was delivered by research health professionals $[5,6]$, and the effect was sustained after three years (report in preparation). The effect was greater than any other intervention of its kind [7].

The NHS Breast Screening Programme currently invites women aged 50-70 for two-view mammography every three years and a national randomised controlled trial of inviting women aged 47-49 and 71-73 is currently under way. The final invited mammogram provides an opportunity to 
promote early presentation to women at increasing risk of developing breast cancer, but no longer routinely invited for screening, at whatever age that may be. By promoting early symptomatic presentation, the PEP Intervention may reduce stage of breast cancer at diagnosis and is unlikely to lead to overdiagnosis: among women aged 70 and over, breast symptoms are very likely to be due to breast cancer [8].

We aimed to examine whether we could train NHS rather than research staff to deliver the PEP Intervention, whether quality of delivery could be maintained, and whether the effect on breast cancer awareness shown in the randomised controlled trial could be replicated in routine clinical practice. We piloted the PEP Intervention, which takes about five minutes, delivered by NHS mammographers as an integral part of the final invited mammogram appointment in four breast screening services.

\section{Methods}

2.1. Training to Deliver PEP Intervention. During 2011, we offered training to deliver the PEP Intervention to all 63 mammographers (both radiographers and assistant practitioners working in four breast screening services (Cambridge and Huntingdon; Warwickshire, Solihull and Coventry; Maidstone; Medway)). The facilitator-led training involved two half-day group sessions, two to four weeks apart, plus practice sessions with performance feedback in-between provided by coaching radiographers. The training team, including the facilitator and coaching radiographers, assessed competence to deliver the PEP Intervention during and at the end of training by completing a checklist of quality criteria (see the appendix) during observed interventions. The coaching radiographer calculated a quality score for each intervention for content out of 33 and for style out of 6 and converted these to percentages. A satisfactory score was considered to be $70 \%$ for content and $50 \%$ for style. Having identified strong and weak areas of quality of delivery, the coaching radiographer undertook a performance feedback session with the mammographer. Twelve of the criteria were considered the most important (nine for content and three for style (marked "essential" and "desirable" on the checklist (see the appendix))) and so performance feedback focused mainly on these.

We measured mammographers' confidence to deliver key messages about early presentation before and immediately after training, using a self-complete questionnaire including seven questions answered on a scale of $1-10$. We calculated mean scores out of ten for each question before and after training.

2.2. Delivering the PEP Intervention. During the implementation period (between three and six months in each service between May 2011 and February 2012), women attending for final mammogram were allocated longer appointments and offered the PEP Intervention on arrival. The PEP Intervention was delivered as an integral part of the final invited mammogram in the X-ray room.

We implemented a quality assurance programme to ensure consistently high-quality delivery of the PEP Intervention. This involved a coaching radiographer assessing, for each mammographer, an audiotaped intervention every two weeks, and a directly observed intervention every two months, using the checklist of quality criteria (see the appendix). The coaching radiographer assessed quality and used this as the basis for a fifteen-minute performance feedback session as described in the section on training to deliver the PEP Intervention.

\subsection{Evaluating the Effect of the PEP Intervention on Breast} Cancer Awareness. Evaluating the effect of the PEP Intervention on breast cancer awareness involved the four pilot services and two comparison services which did not offer the PEP Intervention (Norwich and Norfolk and Gateshead Breast Screening Services). Women were sent information about the evaluation with their final invited screening appointment letter three weeks before their appointment. Mammographers invited eligible women to take part when they attended, and if they consented, they were asked to complete a short questionnaire. One month later we sent them the same questionnaire by post.

The questionnaire included a validated measure of breast cancer awareness [9]. This measured knowledge of breast cancer symptoms, knowledge that the risk of breast cancer increases with age and of lifetime risk of breast cancer, reported breast checking, confidence to detect a breast change, and barriers to seeing a doctor with a health problem. Women were also asked to provide ethnic group, whether they lived with a husband or partner and age of leaving full time education. Breast screening services provided date of birth and postcode.

Breast cancer awareness data collection in the pilot services took place over May 2011 to April 2012 and in the comparison services over March 2011 to January 2012. We compared change in breast cancer awareness over one month in women receiving the PEP Intervention in the pilot services with that of women in the comparison services.

We assigned each woman taking part in the evaluation an Index of Multiple Deprivation score (IMD) (2007) based on the area of residence used in the Census 2001 (higher scores indicate more socioeconomic deprivation: the IMD summarises income, employment, health and disability, education and skills, housing, service access, living environment, and experience of crime, based on a range of routine data sources, for a geographical area). We examined demographic differences between women who received the PEP Intervention and women in the comparison services and between women who responded at one month and women who responded at baseline only.

Women were considered breast cancer aware if they knew that risk of breast cancer increased with age, recognised five or more nonlump symptoms of breast cancer, and reported checking their breasts at least once a month.

We used repeated measures logistic regression models to examine change in breast cancer awareness from baseline to one month comparing women who received the PEP Intervention with women in the comparison services, including only those who provided data at both time points. We examined the effect on the odds ratios of controlling for demographic differences between the groups. 


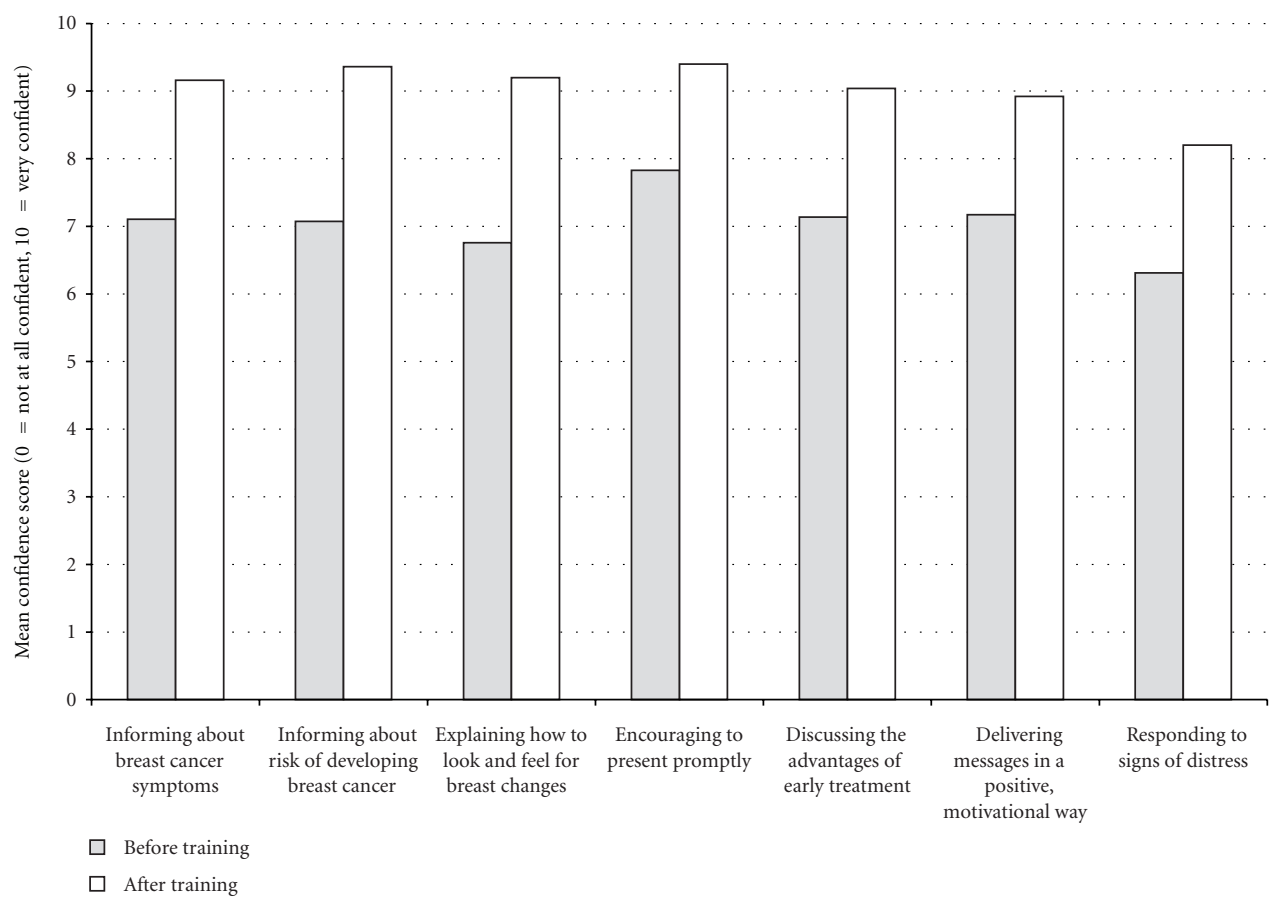

Figure 1: Mammographers' mean confidence scores before and after training.

We carried out semistructured interviews with mammographers several weeks after training to gain their impressions of training, coaching, performance feedback and delivery of the intervention, and how they felt it had contributed to their professional development.

The project received ethics approval from the Cambridgeshire 1 Research Ethics Committee (10/H0304/90).

\section{Results}

Thirty two mammographers started and 27 completed the training programme (five did not complete it because of health problems and family commitments). At the end of training, all 27 were delivering the PEP Intervention to a satisfactory level $(70 \%$ or more for content and $50 \%$ or more for style). Mean confidence scores for all seven questions increased over the training period (Figure 1).

Eight hundred and thirty women were offered the PEP Intervention (25\% of women attending for their final invited mammogram at the four services) and 551 (66\%) took it up. Nineteen mammographers ultimately delivered these interventions - eight were not able to for a variety of personal and service reasons. Quality of delivery was well maintained for these 19 mammographers: based on fortnightly assessments, mean scores for content never fell below $80 \%$ and mean scores for style never fell below $70 \%$.

In the pilot services, 511 women were asked to participate in the evaluation of breast cancer awareness; 495 (97\%) agreed to take part and completed a baseline questionnaire. Four hundred and fifty seven (92\%) women also completed the one-month questionnaire. In one of the comparison services, $880(64 \%)$ women attending for final invited mammogram agreed to take part and completed the baseline questionnaire; 789 (90\%) women also completed the onemonth questionnaire. In the other comparison service, only $82(36 \%)$ women attending for their final invited mammogram agreed to take part and completed the baseline questionnaire. This is likely to have been because mammographers found it difficult to recruit women due to ongoing service developments, in particular the introduction of digital mammography. We did not include the women attending this service in the analysis because of the low response rate.

Women who responded at both time points were more likely to be White and slightly less likely to live in socioeconomically deprived areas than women who responded at baseline only (White: $98 \%$ versus 94\%, $P<0.001$; median IMD 11.1 versus $12.0, P=0.03$ ).

Table 1 shows the demographic characteristics of participating women. Most were White and lived with a husband or partner. Women who received the PEP Intervention were slightly older, less likely to be living with a husband or partner, more likely to have left school after the age of 18 , and less likely to be living in socioeconomically deprived areas than women in the comparison service.

Table 2 shows change in breast cancer awareness and confidence to notice a breast change in the women who received the PEP Intervention and the women in the comparison service. Women who received the PEP Intervention had a much greater increase in breast cancer awareness than the comparison group. The increase was seen for all components of the score: women who received the PEP Intervention were more likely to recognise five or more nonlump symptoms of breast cancer, to know that a 70-year-old woman was most at risk of breast cancer compared to a 30 - or 50-year-old 
TABLE 1: Characteristics of women participating in the evaluation.

\begin{tabular}{|c|c|c|c|}
\hline & $\begin{array}{l}\text { Women in comparison service } \\
\qquad n=875\end{array}$ & $\begin{array}{l}\text { Women receiving PEP Intervention } \\
\qquad n=495\end{array}$ & \\
\hline Mean age & 68 years, 9 months & 71 years, 4 months & $P<0.001$ \\
\hline Living with husband or partner & $670(76.6 \%)$ & $340(68.7 \%)$ & $P<0.001$ \\
\hline Left full time education aged 19 or older & $88(10.1 \%)$ & $109(22.0 \%)$ & $P<0.001$ \\
\hline White ethnic group & $854(97.6 \%)$ & $484(97.8 \%)$ & $P=0.42$ \\
\hline Median Index of Multiple Deprivation & 11.39 & 8.12 & $P<0.001$ \\
\hline
\end{tabular}

TABLE 2: Change in breast cancer awareness and confidence to notice a breast change.

\begin{tabular}{|c|c|c|c|c|c|}
\hline & \multicolumn{2}{|c|}{ Comparison service $(n=789)$} & \multicolumn{2}{|c|}{ PEP Intervention $(n=457)$} & \multirow{2}{*}{ Crude odds ratio ( $95 \%$ confidence interval) } \\
\hline & Baseline & One month & Baseline & One month & \\
\hline Breast cancer aware & $24(2.9 \%)$ & $30(3.9 \%)$ & $19(4.2 \%)$ & $167(37.7 \%)$ & $15.24(10.0$ to 23.2$)$ \\
\hline $\begin{array}{l}\text { Knew five or more } \\
\text { nonlump symptoms }\end{array}$ & 457 (52.2\%) & $461(59.3 \%)$ & $244(52.8 \%)$ & $373(82.5 \%)$ & $3.26(2.48$ to 4.30$)$ \\
\hline $\begin{array}{l}\text { Knew that risk of breast } \\
\text { cancer increases with age }\end{array}$ & $70(8.2 \%)$ & $59(7.6 \%)$ & $66(13.3 \%)$ & $247(49.9 \%)$ & $15.39(11.1$ to 21.35$)$ \\
\hline $\begin{array}{l}\text { Reported checking breasts } \\
\text { at least once a month }\end{array}$ & $494(57.0 \%)$ & $506(64.5 \%)$ & $249(50.3 \%)$ & $359(78.7 \%)$ & $2.10(1.61$ to 2.73$)$ \\
\hline $\begin{array}{l}\text { Knew lifetime risk of breast } \\
\text { cancer ( } 1 \text { in } 8)\end{array}$ & $419(49.2 \%)$ & $372(47.8 \%)$ & $244(50.2 \%)$ & $272(60.4 \%)$ & $1.67(1.32$ to 2.10$)$ \\
\hline $\begin{array}{l}\text { "Fairly" or "very" confident } \\
\text { to notice change in breasts }\end{array}$ & $603(69.6 \%)$ & $619(78.8 \%)$ & $348(70.7 \%)$ & $391(85.6 \%)$ & $1.61(1.19$ to 2.19$)$ \\
\hline
\end{tabular}

woman or a woman of any age and more likely to report checking their breasts at least once a month than women in the comparison service after one month. Women who received the PEP Intervention were also more likely to know the lifetime risk of breast cancer and to report being "fairly" or "very confident" that they would notice a change in their breasts at one month compared with the comparison service. Adjusting for age, living with a husband or partner, age left full time education, and IMD made little difference to the odds ratios.

Barriers to symptomatic presentation were relatively rarely reported by the women (Table 3 ). The most frequently reported issues making it difficult to see a doctor with a health problem were feeling that they were bothering their doctor, finding it difficult to make an appointment and worrying that the doctor is too busy to listen to them. The PEP Intervention had limited influence on barriers; the only statistically significant differences were very small: women who received the PEP Intervention were less likely to report that finding it difficult to make an appointment, that the doctor was too busy to listen to them, and that it was physically difficult to get to the surgery than in the comparison group. Adjusting for age, living with a husband or partner, age left full time education, and IMD made little difference to the odds ratios.

In interviews, mammographers were very positive about training, coaching, performance feedback, and delivery of the PEP Intervention. They saw the PEP Intervention as extending their role, enhancing their professional development, and they particularly valued the opportunity it gave them to interact with their clients.

\section{Discussion}

We successfully piloted implementation of the PEP Intervention in four breast screening services: we trained NHS mammographers who delivered the intervention confidently to a high standard, and who were positive about its effect on their professional development. Uptake of the intervention was good. The intervention increased breast cancer awareness at one month from $4 \%$ at baseline to $38 \%$ at one month. The effect of the intervention on breast cancer awareness in routine clinical practice is of a similar size as achieved by the PEP Intervention delivered within the randomised controlled trial, which increased breast cancer awareness at one month from $2 \%$ at baseline to $33 \%$ at one month [6]. The PEP intervention had large effects on all the aspects of breast cancer awareness. It had a more limited effect on reported barriers to symptomatic presentation.

Our study shows that the PEP Intervention is as potent after one month when delivered in routine clinical practice by NHS staff as when delivered by research radiographers with very close quality control in a randomised controlled trial. We were surprised at this finding: interventions, whether pharmacological or complex, are often less potent in routine clinical practice than in randomised controlled trials [10-12]. There are many possible reasons for this, including that in randomised controlled trials the delivery of the intervention being tested is strictly controlled, and the participants are self-selected and more motivated with better potential for a positive outcome [13]. The success of the PEP Intervention in routine clinical practice is likely to be due to a high level of mammographer motivation engendered by 
TABLE 3: Change in reported barriers to seeing a doctor with a health problem.

\begin{tabular}{|c|c|c|c|c|c|}
\hline & \multicolumn{2}{|c|}{ Comparison service $(n=789)$} & \multicolumn{2}{|c|}{ PEP Intervention $(n=457)$} & \multirow{2}{*}{ Crude odds ratio ( $95 \%$ confidence interval) } \\
\hline & Baseline & One month & Baseline & One month & \\
\hline $\begin{array}{l}\text { I feel that I am bothering } \\
\text { my doctor }\end{array}$ & $74(8.6 \%)$ & $89(11.3 \%)$ & $63(12.8 \%)$ & $50(11.0 \%)$ & 0.95 (0.66 to 1.37$)$ \\
\hline $\begin{array}{l}\text { It is usually difficult for me } \\
\text { to get an appointment }\end{array}$ & $67(7.7 \%)$ & $99(12.6 \%)$ & $32(6.5 \%)$ & $30(6.6 \%)$ & $0.48(0.32$ to 0.74$)$ \\
\hline $\begin{array}{l}\text { I worry that he/she is too } \\
\text { busy to listen to me }\end{array}$ & $38(4.4 \%)$ & $61(7.8 \%)$ & $25(5.1 \%)$ & $21(4.6 \%)$ & $0.59(0.35$ to 0.98$)$ \\
\hline $\begin{array}{l}\text { I worry about any } \\
\text { treatment I might have to } \\
\text { have }\end{array}$ & $27(3.1 \%)$ & $43(5.5 \%)$ & $28(5.7 \%)$ & $24(5.3 \%)$ & $0.95(0.57$ to 1.59$)$ \\
\hline $\begin{array}{l}\text { I feel embarrassed to go to } \\
\text { my doctor in case he/she } \\
\text { has to examine me }\end{array}$ & $18(2.1 \%)$ & $19(2.4 \%)$ & $8(1.6 \%)$ & $13(2.9 \%)$ & $1.18(0.57$ to 2.43$)$ \\
\hline $\begin{array}{l}\text { I have other more } \\
\text { important things to think } \\
\text { about or do }\end{array}$ & $17(2.0 \%)$ & $23(2.9 \%)$ & $16(3.3 \%)$ & $15(3.3 \%)$ & $1.15(0.60$ to 2.18$)$ \\
\hline $\begin{array}{l}\text { It is physically difficult for } \\
\text { me to get to the surgery }\end{array}$ & $10(1.2 \%)$ & $13(1.7 \%)$ & $3(0.6 \%)$ & $1(0.2 \%)$ & $0.18(0.03-0.96)$ \\
\hline
\end{tabular}

the training and coaching, and attributes of the intervention itself, which gives the mammographers an opportunity to communicate positively with their clients.

We found that the PEP Intervention had little effect on reported barriers to symptomatic presentation. This may be at least partly because barriers were rarely reported by the women. We note that the commonest barrier to early presentation reported was "I feel I am bothering my doctor," reported by about $11 \%$ of women. This is less than has been found in other studies of barriers to symptomatic presentation asking a similar question, which have found that over $30 \%$ of British people reported that worry about wasting the doctor's time might put them off seeing a doctor with a symptom that might be serious $[14,15]$.

Our evaluation of the pilot implementation of the PEP Intervention was not as methodologically robust as the randomised controlled trial: in the pilot, women were not randomly allocated to receive the intervention or not, so those receiving the intervention may have differed in many ways from those who did not, in the comparison services. However, adjusting for known differences between the women in the intervention and comparison services made little difference to the findings. Moreover, the effect size was so large that variation in outcome between the intervention and comparison services is unlikely to be due simply differences between the populations involved.

Implementation was not complete: the services did not manage to offer the PEP Intervention to all women attending for final mammogram. This was because not all mammographers were trained to deliver the intervention, and implementation was limited by the capacity of existing clinics and availability of temporary staff to backfill the trained mammographers' time. Were the intervention to be implemented more widely, it would be necessary to expand capacity of the services to incorporate an extra five minutes for every woman attending for their final invited mammogram (about 1 in 7 mammograms delivered).

Uptake of the intervention among women was good, suggesting that the intervention was an acceptable part of the mammogram appointment.

Whether increasing breast cancer awareness will reduce breast cancer mortality is not yet known. The evaluation is ongoing and will, in due course, report the effect on breast cancer awareness at one year, self-referral for screening, symptomatic breast clinic attendances, and breast cancer mortality. There is indirect evidence that breast cancer awareness influences mortality: women who delay presentation in breast cancer are more likely to have poor awareness of symptoms [3], and delay in diagnosis is related to worse survival in breast cancer [16].

The UK has worse breast cancer survival than many countries with good access to high-quality health care [17]. We estimate that 7,000-12,000 women in England delay presentation for $>3$ months each year $[16,18]$. These women have $7 \%$ lower 5 -year survival than those with shorter delays [16]. This suggests that at least 500 women in England will die because of delayed presentation each year (assuming a 5year breast cancer survival of $80 \%$ in women who delay $<3$ months and $73 \%$ in those who delay $>3$ months). Delivered to all women attending for their final invited mammogram on the NHS Breast Screening Programme, at whatever age that may be, the PEP Intervention could contribute to improving cancer survival in England so that it is nearer to that achieved in similar countries.

\section{Appendix}

For quality criteria to assess mammographers' competence to deliver the intervention see Supplementary Material available online at doi:10.1155/2012/835167. 


\section{Conflict of Interests}

The authors declare that they have no conflict of interests.

\section{Acknowledgments}

This work was funded by NHS Cancer Screening Programmes and the National Institute for Health Research, through the West Anglia Local Cancer Research Network. The women who took part: Cambridge and Huntingdon: Dr. Matthew Wallis, Barbara Knighton, Judith Fatibene, Valerie Hopkins, Latch Raghubans, and Lesley Rowlands; Gateshead: Dr. Linsley Lunt, Janet Cumiskey, and Allison Wise; Maidstone: Dr. Pippa Mills, Ray Nuttal, Sandra Bowman, Caroline Wendholt, Michelle Allen, Julie Buckley, Shauna Dunn, Sharon Jones, Lynne Kettle, Jane Moore, and Julie Trevers; Medway: Miss Delilah Hassanally, Daphne van den Heever, Janet Norwood, Jenny Barrett, Lydia Chadwick, Linda Conisbee, Sue Hussain, Stephanie Janulewicz, Jocelyn Jaudalso, Wilma Manalac, Tracey Pepler, Olivia Taylor-Fry, Lynn Todd, and Sue Wallbridge; Norfolk and Norwich: Dr. Simon Girling, Rachel Hiscock, and Mandy Ballantyne; Warwickshire, Solihull, and Coventry: Dr. Alison Duncan, Anita Stanton, Sharon Hoffmeister, Margot Wheaton, Marie Goodison, Brenda McCole, Jackie McKay, Toni Scanlon, Cathy Williams, and Lynn Worthington.

\section{References}

[1] H. Møller, F. Sandin, F. Bray et al., "Breast cancer survival in England, Norway and Sweden: a population-based comparison," International Journal of Cancer, vol. 127, no. 11, pp. 2630-2638, 2010.

[2] G. Lyratzopoulos, G. A. Abel, J. M. Barbiere, C. H. Brown, B. A. Rous, and D. C. Greenberg, "Variation in advanced stage at diagnosis of lung and female breast cancer in an English region 2006-2009," British Journal of Cancer, vol. 106, no. 6, pp. 1068-1075, 2012.

[3] A. Ramirez, A. M. Westcombe, C. C. Burgess, S. Sutton, P. Littlejohns, and M. A. Richards, "Factors influencing delayed presentation of breast cancer: a systematic review," The Lancet, vol. 353, no. 9159, pp. 1127-11131, 1999.

[4] C. C. Burgess, A. M. Bish, H. S. Hunter et al., "Promoting early presentation of breast cancer: development of a psychoeducational intervention," Chronic Illness, vol. 4, no. 1, pp. 1327, 2008.

[5] L. J. L. Forbes, L. Linsell, L. Atkins et al., "A promoting early presentation intervention increases breast cancer awareness in older women after 2 years: a randomised controlled trial," British Journal of Cancer, vol. 105, no. 1, pp. 18-21, 2011.

[6] L. Linsell, L. J. L. Forbes, M. Kapari et al., "A randomised controlled trial of an intervention to promote early presentation of breast cancer in older women: effect on breast cancer awareness," British Journal of Cancer, vol. 101, no. 2, pp. S40S48, 2009.

[7] J. Austoker, C. Bankhead, L. J. L. Forbes et al., "Interventions to promote cancer awareness and early presentation: systematic review," British Journal of Cancer, vol. 101, no. 2, pp. S31-S39, 2009.

[8] G. C. Wishart, J. Warwick, V. Pitsinis, S. Duffy, and P. D. Britton, "Measuring performance in clinical breast examination," British Journal of Surgery, vol. 97, no. 8, pp. 1246-1252, 2010.
[9] L. Linsell, L. J. L. Forbes, C. Burgess, M. Kapari, A. Thurnham, and A. J. Ramirez, "Validation of a measurement tool to assess awareness of breast cancer," European Journal of Cancer, vol. 46, no. 8, pp. 1374-1381, 2010.

[10] J. S. Routman, J. H. Willig, A. O. Westfall et al., "Comparative efficacy versus effectiveness of initial antiretroviral therapy in clinical trials versus routine care," Clinical Infectious Diseases, vol. 50, no. 4, pp. 574-584, 2010.

[11] R. van der Lem, N. J. van der Wee, T. van Veen, and F. G. Zitman, "Efficacy versus effectiveness: a direct comparison of the outcome of treatment for mild to moderate depression in randomized controlled trials and daily practice," Psychotherapy and Psychosomatics, vol. 81, no. 4, pp. 226-234, 2012.

[12] R. Thomson, "Evidence based implementation of complex interventions," British Medical Journal, vol. 339, Article ID b3124, 2009.

[13] B. K. Nallamothu, R. A. Hayward, and E. R. Bates, "Beyond the randomized clinical trial. The role of effectiveness studies in evaluating cardiovascular therapies," Circulation, vol. 118, no. 12, pp. 1294-1303, 2008.

[14] L. J. L. Forbes, L. Atkins, A. Thurnham, J. Layburn, F. Haste, and A. J. Ramirez, "Breast cancer awareness and barriers to symptomatic presentation among women from different ethnic groups in East London," British Journal of Cancer, vol. 105, pp. 1474-1479, 2011.

[15] K. Robb, S. Stubbings, A. Ramirez et al., "Public awareness of cancer in Britain: a population-based survey of adults," British Journal of Cancer, vol. 101, no. 2, pp. S18-S23, 2009.

[16] M. A. Richards, A. M. Westcombe, S. B. Love, P. Littlejohns, and A. J. Ramirez, "Influence of delay on survival in patients with breast cancer: a systematic review," The Lancet, vol. 353, no. 9159, pp. 1119-1126, 1999.

[17] M. P. Coleman, D. Forman, H. Bryant et al., "Cancer survival in Australia, Canada, Denmark, Norway, Sweden, and the UK, 1995-2007 (the international cancer benchmarking partnership): an analysis of population-based cancer registry data," The Lancet, vol. 377, no. 9760, pp. 127-138, 2011.

[18] Office for National Statistics, Cancer Registration Statistics England 2008, Office for National Statistics, Newport, UK, 2010. 


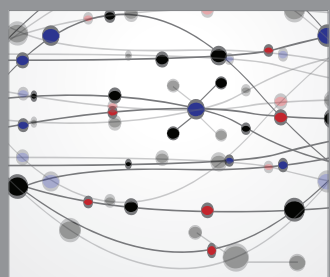

The Scientific World Journal
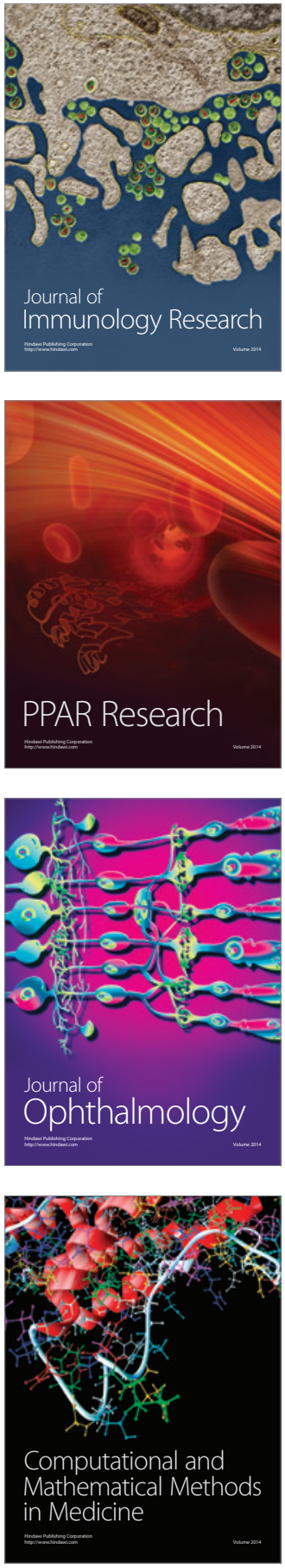

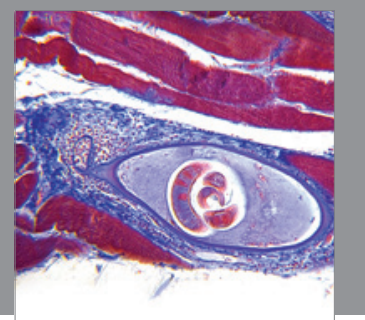

Gastroenterology

Research and Practice
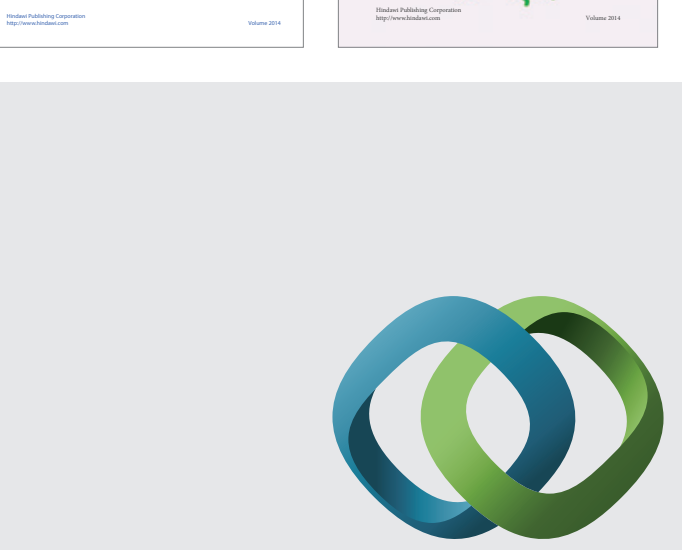

\section{Hindawi}

Submit your manuscripts at

http://www.hindawi.com
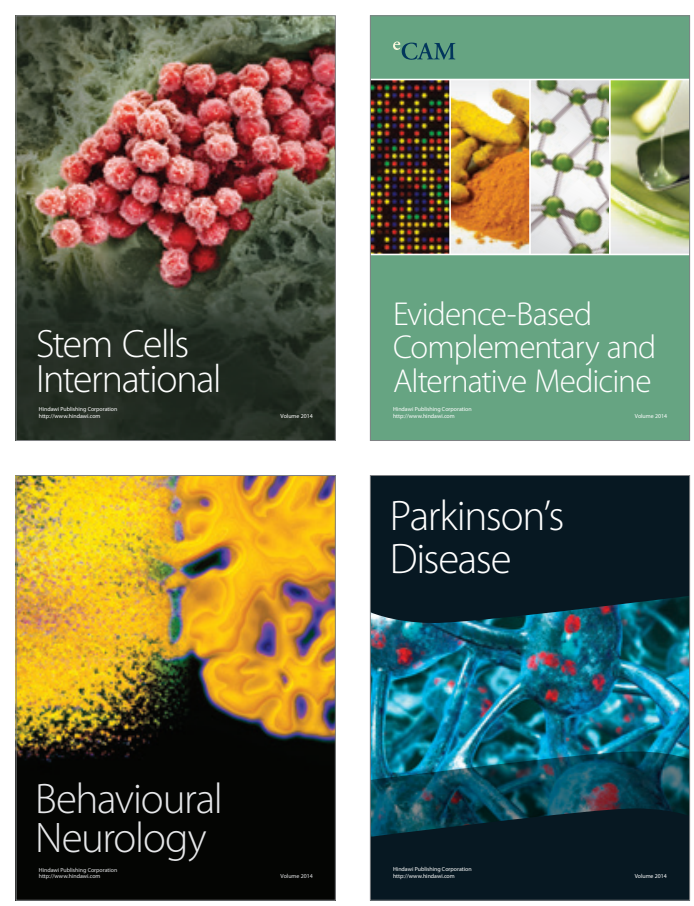

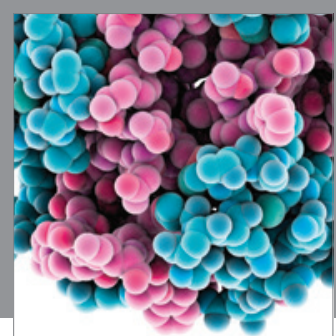

Journal of
Diabetes Research

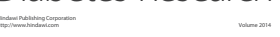

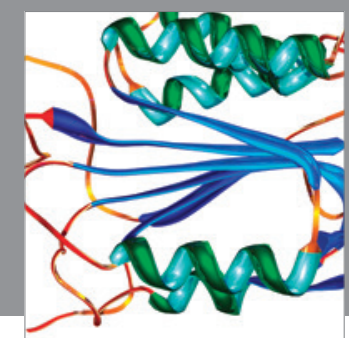

Disease Markers
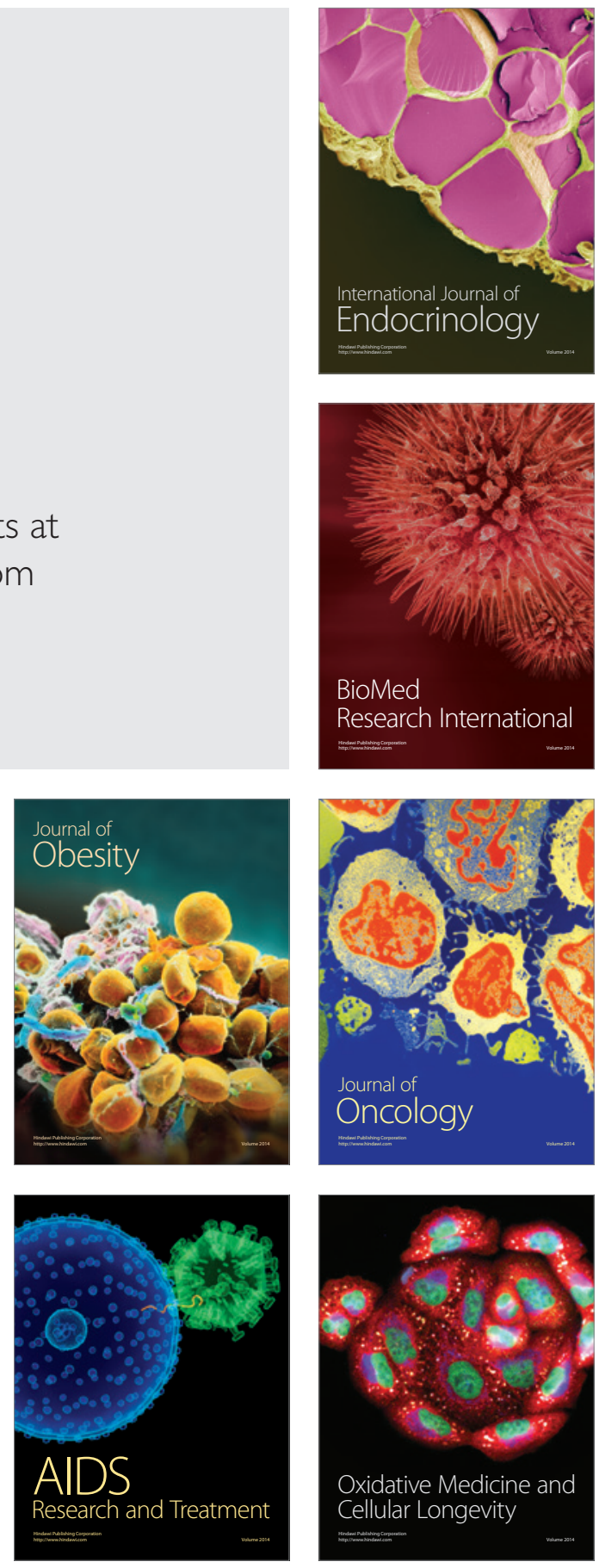